\title{
Molecular Mapping of the Major Resistance Quantitative Trait Locus $q H S 2.09$ with Simple Sequence Repeat and Single Nucleotide Polymorphism Markers in Maize
}

\author{
Jianfeng Weng, Xianjun Liu, Zhenhua Wang, Jianjun Wang, Lin Zhang, Zhuanfang Hao, \\ Chuanxiao Xie, Mingshun Li, Degui Zhang, Li Bai, Changlin Liu, Shihuang Zhang, and Xinhai Li
}

First, sixth, seventh, eighth, ninth, tenth, eleventh, twelfth, and thirteenth authors: Institute of Crop Science, National Key Facility for Crop Gene Resources and Genetic Improvement, Chinese Academy of Agricultural Sciences, Zhongguancun South Street, Beijing 100081, China; second, third, and fifth authors: Northeast Agricultural University, Harbin 150030, Heilongjiang Province, China; and fourth author: Maize Research Institute, Shanxi Academy of Agricultural Sciences, Xinzhou 034000, China.

Accepted for publication 13 March 2012.

\begin{abstract}
Weng, J., Liu, X., Wang, Z., Wang, J., Zhang, L., Hao, Z., Xie, C., Li, M., Zhang, D., Bai, L., Liu, C., Zhang, S., and Li, X. 2012. Molecular mapping of the major resistance quantitative trait locus qHS2.09 with simple sequence repeat and single nucleotide polymorphism markers in maize. Phytopathology 102:692-699.

The major quantitative trait locus (QTL) qHS2.09 plays an important role in resistance to head smut during maize breeding and production. In this study, a near-isogenic line (NIL), L34, which harbors the major QTL $q H S 2.09$ in bin 2.09, was developed using a resistant donor 'Mo17' in a susceptible genetic background 'Huangzao4'. Using 18,683 genome-wide polymorphic loci, this major QTL was finely mapped into an interval of

from 'Mo17' for SNP PZE-102187611 in this interval that was most significantly associated with resistance to head smut $(P=1.88 \mathrm{E}-10)$ and accounted for 39.7 to $44.4 \%$ of the phenotypic variance in an association panel consisting of 80 inbred lines. With combined linkage and association mapping, this major QTL was finally located between SNP PZE-102187486 and PZE-102188421 with an interval of $\approx 1.00 \mathrm{Mb}$. Based on the pedigrees of 'Mo17' and its derivatives widely used in temperate maize breeding programs, the favorable haplotype from 'Mo17' is shown to be the main source of resistance to head smut in these lines. Therefore, the SNPs closely linked to the major QTL qHS2.09, detected in both linkage and association mapping, and could be useful for marker-assisted selection in maize breeding programs.
\end{abstract} $\approx 1.10 \mathrm{Mb}$, flanked by single nucleotide polymorphism (SNP) markers PZE-102187307 and PZE-102188421. Moreover, the favorable allele

Head smut, caused by Sporisorium reiliana (Kühn) Clint, is a serious maize disease, particularly where maize is grown under low temperatures or at high latitude $(5,24)$. The spring maizegrowing region in northeastern China, where weather conditions and farming systems are conducive for disease development, is a major head smut epiphytotic region of the world (19). Due to the high costs and environmental concerns to chemical management agents, resistance breeding is a more efficient, economical, and sustainable means for controlling the disease (22).

Resistant germplasm and gene banks hold the keys to the successful breeding of improved crop cultivars with durable resistance to disease (15). To date, several resistant inbred lines and germplasms have been identified in field studies under natural and artificial inoculation conditions $(11,16,33,34,36)$, and the Lancaster subgroup has been identified as the most important source of resistance to $S$. reiliana in China (36).

With the application of molecular markers in quantitative trait locus (QTL) analysis, a number of resistance loci to various diseases, including southern leaf blight (SLB), gray leaf spot (GLS), and northern leaf blight (NLB) $(3,4,8,17,18,29,38,41,43)$ have been detected by maize linkage mapping. Moreover, diverse genetic resources have facilitated research into the disease resistance

Corresponding authors: S. Zhang and X. Li; E-mail addresses:

cshzhang2000@yahoo.com.cn and lixh2008caas@yahoo.cn

J. Weng, X. Liu, and Z. Wang contributed equally to this work.

http://dx.doi.org/10.1094/PHYTO-12-11-0330

(C) 2012 The American Phytopathological Society
Additional keywords: fine mapping, genome-wide association, Zea mays.

genes in maize, including the $H t$ gene for NLB resistance (37), the $R p$ gene for rust resistance (31), the glutathione $S$-transferase gene for multiple disease resistance (39), etc. Resistance to head smut is a complex quantitative trait under polygenic inheritance (1). QTL mapping has located one major resistance QTL on chromosome 2, in addition to other minor QTL identified on all other chromosomes except for chromosome $7(9,18,21,24)$. We previously reported a major QTL in bin 2.09 that explains up to $43.7 \%$ of the phenotypic variance and confers resistance to head smut in a population of $184 \mathrm{~F}_{2: 3}$ families derived from a cross between 'Mo17' and 'Huangzao4' (21). This major resistance QTL, designated $q H S R 1$, was also revealed to be flanked by markers simple sequence repeats (SSR)148152 and STS661 in the 'Mo17' derivative inbred line 'Ji1037' (9). Therefore, it will be important to finely map this major QTL and to identify closely linked markers useful in molecular marker-assisted selection for head smut resistance in maize.

Association mapping has been a powerful complement to classical mapping in bi-parental crosses as a strategy to detect quantitative trait loci underlying complex traits in plants. In Arabidopsis, the power of association studies for complex traits has been demonstrated using 107 phenotypes and 250,000 single nucleotide polymorphisms (SNPs) (2). In barley, the HvbHLH1 gene that encodes a protein involved in anthocyanin pigmentation was finely mapped within a $140 \mathrm{~kb}$ interval in a genome-wide association study using 1536 SNPs derived from expressed sequence tags (10). In rice, six significant loci harboring candidate genes for grain shape (GS3 and GW5/qSW5), seed color (OsC1 and $R c$ ), amylose content $(W x)$, and gelatinization temperature 
$(A L K)$ were identified in an association study using $\approx 3.6$ million SNPs in a panel of 517 rice landraces (14). In maize, association mapping in 350 tropical and subtropical maize inbreds with 1229 SNPs from 540 candidate genes for drought resistance identified allelic variations in three genes, which encoded a MADS-box (PISTILLATA) protein, a pyruvate dehydrogenase kinase, and an aldehyde oxidase involved in ABA and carbohydrate metabolism in floral tissues during drought stress (32). With 253 maize inbred lines, a glutathione $S$-transferase gene was found to be associated with multiple disease resistance to SLB, GLS, and NLB (39). Using a nested association mapping (NAM) population in maize, loci associated with effects on SLB (17), NLB (29) flowering time (7), and leaf architecture (35) have been detected using 1.6 million SNPs (12).

When combined, linkage mapping and genome-wide association have been even more powerful approaches to identify candidate QTLs for complex disease traits. For example, natural allelic variation for resistance to downy mildew has been detected in Arabidopsis (27) using such a combined approach. In maize, particularly, NAM has been used for disease resistance with a combined QTL mapping and association mapping approach $(17,29)$. The objectives of this study were to (i) finely map the major QTL $q H S 2.09$ with SSR and SNP markers in five nearisogenic lines, (ii) perform a genome-wide association study of head smut resistance using 41,101 SNP markers in 80 Chinese elite maize inbred lines, and (iii) examine the favorable haplotype for head smut resistance in inbred line 'Mo17' and its derivatives. Knowledge of the genetic basis of head smut resistance will facilitate selection of resistance genes for this disease in maize breeding.

\section{MATERIALS AND METHODS}

Plant materials. In this study, five near-isogenic lines, L34, L52, L162, L163, and L170, were developed from the $\mathrm{BC}_{4} \mathrm{~F}_{2}$ with the susceptible background ('Huangzao4') carrying the major resistance QTL from the resistant donor line ('Mo17') in bin 2.09 using SSR marker-assisted selection (Fig. 1). A total of 80 inbred lines representing two subgroups identified by population structure analysis (42), LAN (Lancaster Sure Crop), and SPT (lines derived from Si-ping-tou, a Chinese landrace) (Table 1) were used in this genome-wide association study. 'Mo17' and 'Huangzao4' were the key maize inbred lines in these two subgroups, respectively (42).

Evaluation of resistance against $S$. reiliana. Resistance responses of the maize inbred lines to $S$. reiliana infection were recorded after artificial inoculation in the field from August to September 2009 and 2010 at Harbin, Heilongjiang Province, China $\left(45.8^{\circ} \mathrm{N}, 126.5^{\circ} \mathrm{E}\right)$. The lines were planted in randomized complete blocks with two replicates. Each plot consisted of two $5 \mathrm{~m}$ rows with $0.67 \mathrm{~m}$ between rows, which were over-planted and later thinned to 25 plants per row. Artificial inoculation was performed by sowing seed together with $0.1 \%$ S. reiliana inoculum. Sori containing teliospores of $S$. reiliana were collected from the field during the previous growing season and stored in cloth bags in a dry and well-ventilated environment. Normal agronomic practices were used in field management (40). At maturity, each plant was scored for $S$. reiliana sori when disease symptoms were fully expressed, and the mean of two replicates per plot (21) was subjected to further analysis as described below in genotypephenotype association mapping.

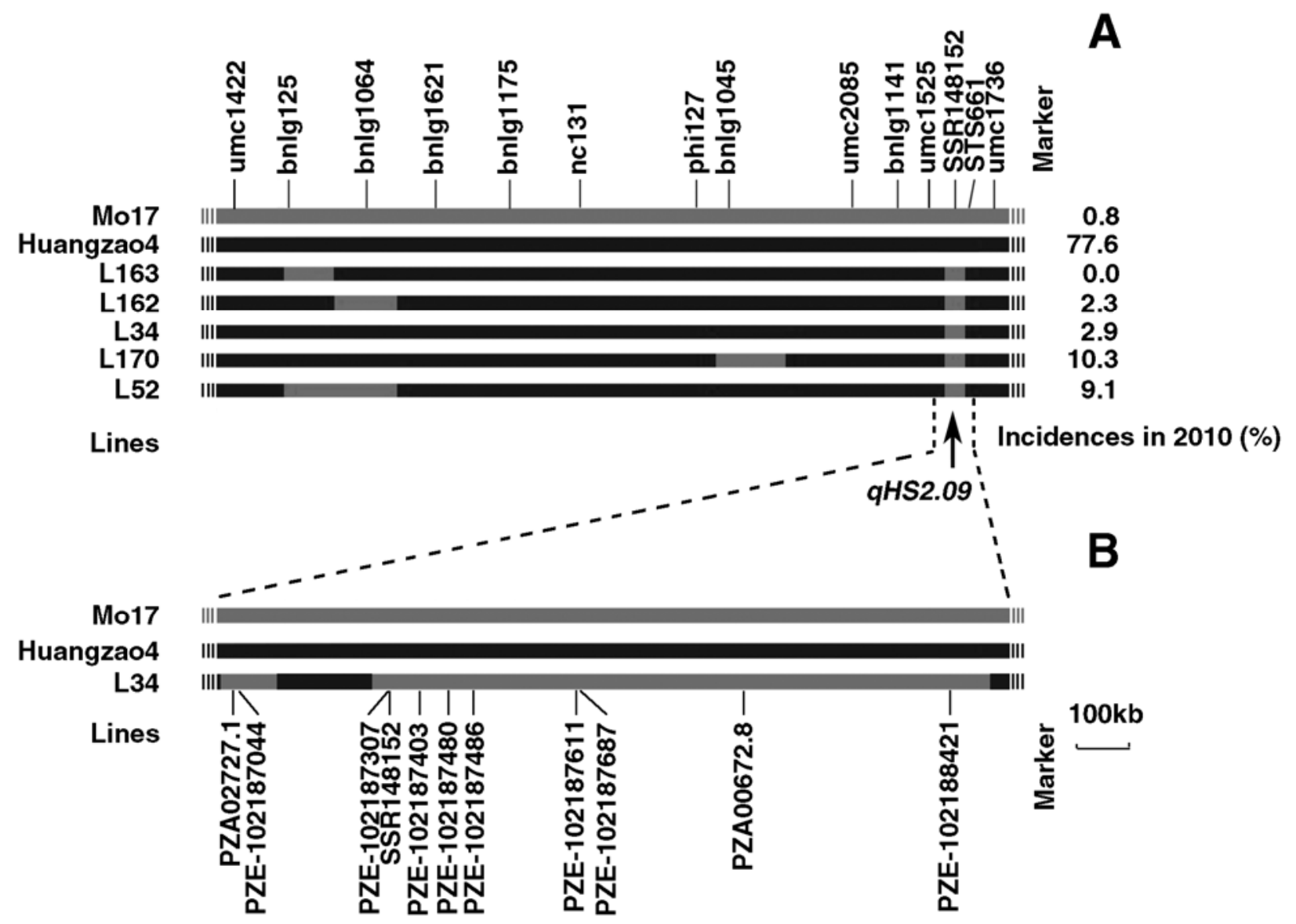

Fig. 1. Fine mapping of the major quantitative trait locus $q H S 2.09$ associated with reduced disease incidence for head smut, with A, simple sequence repeats and B, single nucleotide polymorphism markers on chromosome 2. The gray bars indicate the chromosome regions from 'Mo17', and black bars indicate the regions from 'Huangzao4'. Mean disease incidence for near-isogenic lines in 2010 is indicated by the number on the right of the bars. The names of near-isogenic lines are indicated on the left of the bars. 
SSR assay. Genomic DNA of near-isogenic lines was extracted from the upper two leaves of 20-day-old plants from nearisogenic and parental lines ('Huangzao4' and 'Mo17') using the CTAB procedure (26). One hundred and twenty-five polymorphic simple sequence repeat (SSR) markers evenly distributed on 10 chromosomes, published in a previous study $(9,21)$, were used for marker-assisted selection of the qHS2.09 locus and its genetic background in subpopulations. Polymerase chain reaction (PCR) was performed using a PTC-200 Thermal Cycler (Bio$\mathrm{Rad})$. A total volume of $10 \mu \mathrm{l}$ of reaction mixture composed of 10 ng of genomic DNA, $1 \times$ reaction buffer (Tiangen, Beijing, China), $2.0 \mathrm{mM} \mathrm{MgCl}$, $1 \mathrm{U}$ of Taq DNA polymerase (Tiangen, Beijing, China), $0.1 \mathrm{mM}$ of dNTPs (Tiangen, Beijing, China), and $0.9 \mathrm{mM}$ primers. PCR cycle conditions included an initial denaturation at $94^{\circ} \mathrm{C}$ for $4 \mathrm{~min}$, followed by 35 cycles of denaturation at $94^{\circ} \mathrm{C}$ for $1 \mathrm{~min}$, annealing at 55 or $58^{\circ} \mathrm{C}$ for $30 \mathrm{~s}$, extension at $72^{\circ} \mathrm{C}$ for $1 \mathrm{~min}$, and final extension at $72^{\circ} \mathrm{C}$ for $7 \mathrm{~min}$. Amplification products were resolved by electrophoresis on $10 \%$ polyacrylamide denaturing gels at $150 \mathrm{~V}$ for $2 \mathrm{~h}$, and the bands were silver-stained, and photographically recorded for analysis.

Genotyping. SNP genotyping was performed using the MaizeSNP50 BeadChip processed by Emei Tongde (Beijing). The SNP content featured on this chip, using 56,110 evenly spaced SNPs to cover the entire maize genome according to the B73 genome reference sequence, was selected from several public and private sources with 984 negative controls (Illumina, Inc.). DNA from these 80 maize inbred lines was extracted by a modified CTAB procedure according to a previous report (26), and prior to genotyping, DNA quality for each sample was carefully checked using electrophoresis and a spectrophotometer (Nanodrop 2000, Thermo Scientific). The SNP genotyping of these 80 lines was performed according to the Infinium HD assay ultra-protocol guide (Illumina, Inc.).

Linkage mapping. In the previous result, the major QTL qHS2.09 was mapped into an interval between markers SSR148152 and STS661 in bin 2.09 (9,21). Five NILs harboring the major resistance QTL in bin 2.09 were generated using 125 SSR markers in a $\mathrm{BC}_{4} \mathrm{~F}_{2}$ population. The line $\mathrm{L} 34$, 'Mo17', and 'Huangzao4' were analyzed using 56,110 high-density genomewide SNP markers. The location of the major QTL $q H S 2.09$ was then narrowed into an interval between two outermost SNP markers, which were derived from the donor lines in bin 2.09. Compared with the physical position of SSR and SNP markers, this QTL was finally mapped.

Genotype-phenotype association mapping. SNP alleles were calculated using PowerMarker 3.25 (23). The population structure and kinship information of 80 lines for a mixed linear model (MLM) were input using the softwares STRUCTURE version 2.3 (30) and SPAGeDi (13), respectively, with 5,000 SNPs (minor allele frequencies, MAF $\geq 0.2$ ). STRUCTURE was run to test $\mathrm{K}=$ 2 according to our previous study (42) three times with a burn-in

TABLE 1. Analysis of the pedigrees and disease incidences for 80 inbred lines in the association panel in 2009 and 2010

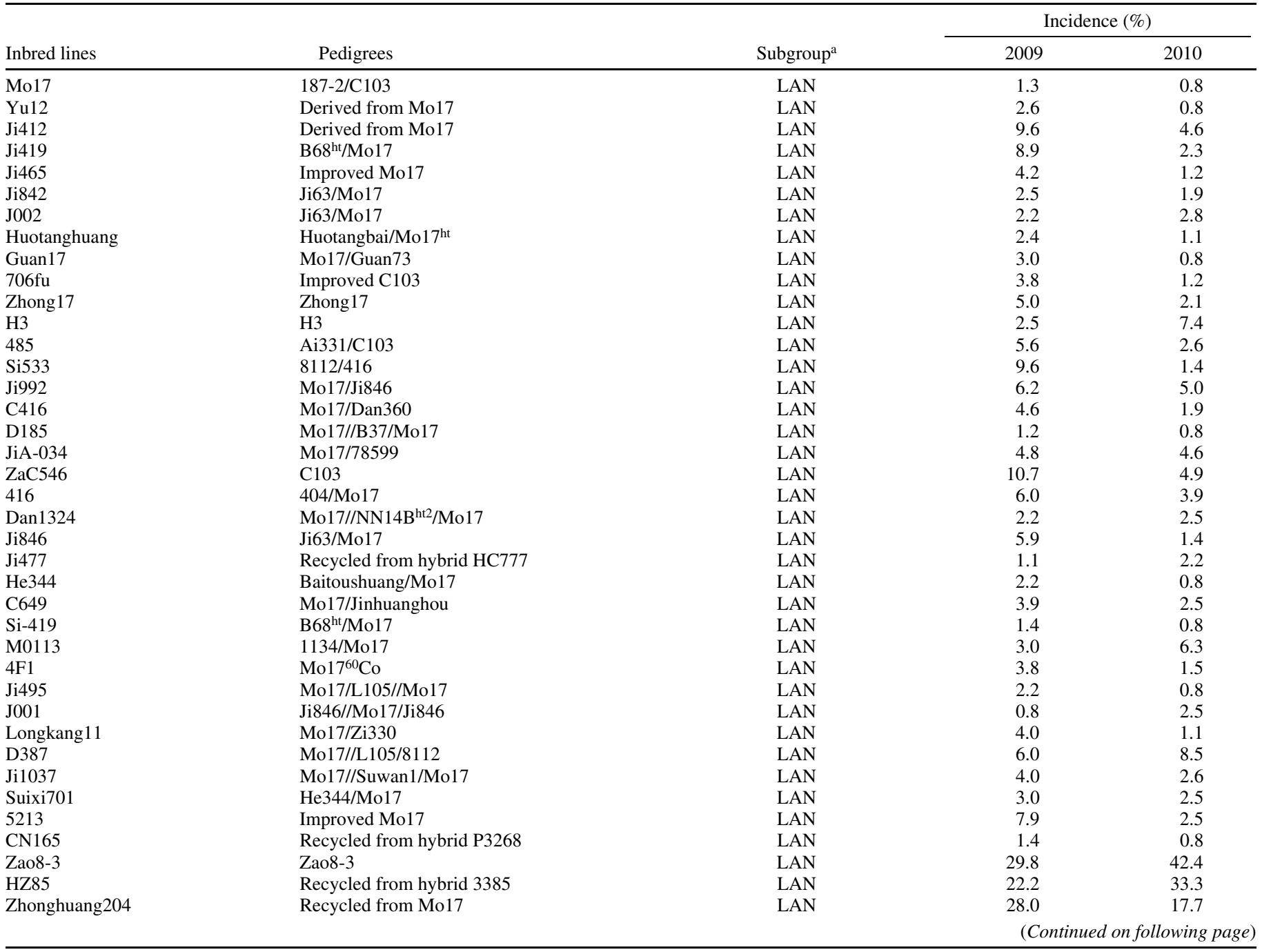

${ }^{a}$ LAN is the Lancaster subgroup, SPT is the subgroup from Si-ping-tou germplasm. 
period of 500,000 and 500,000 replications. The MLM implemented in the program TASSEL 3.0 version (6) was used for association mapping with 41,101 SNPs (MAF $\geq 0.05$ ) in these 80 inbred lines.

\section{RESULTS}

Molecular mapping of the major resistance QTL $q H S 2.09$ with SSR markers. Using previous QTL mapping results, five NILs harboring the marker SSR148152 in bin 2.09 from 'Mo17' were generated by selecting for 125 polymorphic SSR markers in a $\mathrm{BC}_{4} \mathrm{~F}_{2}$ population. The recovery rate for the genetic background of 'Huangzao4' in these five lines was more than $96.9 \%$. Under field conditions using artificial inoculation in 2010, disease incidence in these five NILs was significantly decreased relative to that of 'Huangzao4', from 77.6 to $4.9 \%$. Only one homologous introgression fragment was detected on chromosome 2 in L34, so this line was chosen for beadchip analysis (Fig. 1A).

Validation of the QTL $\boldsymbol{q H S 2 . 0 9}$ with SNP markers. Using the MaizeSNP50 BeadChip, 18,683 genome-wide SNP loci between 'Mo17' and 'Huangzao4' were generated and 10 loci were found to be polymorphic between L34 and 'Huangzao4'. Furthermore, two adjacent introgression fragments were shown to have been transmitted from 'Mo17' into L34. The major QTL for head smut resistance was finally narrowed into an interval of $\approx 1.10 \mathrm{Mb}$, flanked by SNPs PZE-102187307 and PZE102188421 (Fig. 1B).
Genome-wide association study of resistance to head smut. Disease incidence for 80 inbred lines in 2009 and 2010 was significantly correlated $(P<1.00 \mathrm{E}-04)$, and the continuous distribution of disease incidence indicated quantitative inheritance of resistance to head smut (Table 1). Differences in mean disease incidence have been detected, with the lower level, $8.7 \%$, in the Lancaster subgroup, and $40.1 \%$ in the Si-ping-tou subgroup, which suggested that the resistance genes originated from the Lancaster subgroup, especially the derivatives of 'Mo17' (Table 1). Ten SNPs across 10 chromosomes were significantly associated with disease incidence $(P \leq 1.00 \mathrm{E}-04)$ in 2009 and 2010 , and among these, SNP PZE-102187611 in bin 2.09 was most significant. Three QTLs (SNP $P \leq 1.00$ E-04) conferring resistance to head smut, designated $q H S 1.03, q H S 2.09$, and $q H S 4.03$, were detected on chromosomes 1,2 , and 4, respectively, in this association panel (Fig. 2; Table 2). The QTL $q H S 2.09$ within this region containing four closely linked SNP loci was the major locus associated with response to $S$. reiliana infection. With combined linkage and association mapping, the $q H S 2.09$ was finally mapped into an interval of $\approx 1.00 \mathrm{Mb}$ between SNP PZE102187486 and PZE-102188421. The QTL $q H S 1.03$, associated with SNP PZE-101045549, was detected in 2009 and 2010, and $q H S 4.03$, associated with SNP SYNGENTA6546, was detected only in 2010 (Fig. 2; Table 2).

SNP PZE-102187687, which has three genotypes (AA/CC/--), and located adjacent to SNP PZE-102187611, was not significantly associated with head smut resistance (Table 2). However,

TABLE 1. (Continued from preceding page)

\begin{tabular}{|c|c|c|c|c|}
\hline \multirow[b]{2}{*}{ Inbred lines } & \multirow[b]{2}{*}{ Pedigrees } & \multirow[b]{2}{*}{ Subgroup $^{a}$} & \multicolumn{2}{|c|}{ Incidence (\%) } \\
\hline & & & 2009 & 2010 \\
\hline CA091 & $505 / 02 / 7091 / / 7091$ & LAN & 25.7 & 14.9 \\
\hline Zao49 & He344/Taixi138 & LAN & 63.8 & 53.5 \\
\hline Liaobai371 & Recycled from hybrid & LAN & 89.7 & 68.0 \\
\hline Huangzao4 & Tangsipingtou & SPT & 78.4 & 63.3 \\
\hline Wenhuang & Huangzao4/Wenqing1331 & SPT & 82.2 & 65.2 \\
\hline Danhuang02 & LvDa Red Cob Group & SPT & 89.1 & 74.9 \\
\hline CN962 & Recycled from Huangzao4 & SPT & 53.8 & 46.1 \\
\hline Luyuan 133 & Qi721/Huangzao4 & SPT & 20.5 & 12.5 \\
\hline 196 & Huangzao4/Dan340 & SPT & 78.1 & 56.7 \\
\hline H201 & Dan340/Ye515//Huangzao4 & SPT & 14.1 & 13.3 \\
\hline $7379-2$ & Jingyu 1 & SPT & 72.4 & 48.6 \\
\hline H152 & Huangzao4/Mo17//F28/150 & SPT & 68.8 & 44.8 \\
\hline PI143 & Aiyuan311/Lu9801//Chang7-2 & SPT & 87.6 & 72.2 \\
\hline Tangsipingtou & Sipingtou germplasm & SPT & 55.4 & 30.5 \\
\hline PI42 & Huangzao4/LU9801//Chang7-2 & SPT & 78.8 & 62.4 \\
\hline J9206 & 444/Danhuang02 & SPT & 42.0 & 38.0 \\
\hline Sizhisi & Huangzao4/Zi334//Huangzao4 & SPT & 23.5 & 15.4 \\
\hline $\mathrm{H} 21$ & Huangzao4/H84 & SPT & 74.6 & 48.8 \\
\hline Chang7-2 & Huangzao4/Wei59//S901 & SPT & 80.0 & 69.3 \\
\hline Jing7 & Huangzao4/Luoxi3 & SPT & 62.5 & 47.6 \\
\hline Huangyesi & Yejihong/Huangzao4//Dunzihuang & SPT & 39.2 & 34.5 \\
\hline 444 & Huangzao4/A619ht & SPT & 46.7 & 36.5 \\
\hline K12 & Huangzao4/Weichun & SPT & 57.3 & 31.5 \\
\hline Ye502 & Huangzao4/Dan340 & SPT & 76.8 & 65.8 \\
\hline Ye515 & Huafeng100/C103//Huangzao4 & SPT & 40.7 & 38.5 \\
\hline Dhuang212 & D729/Huangzao4 & SPT & 88.4 & 68.8 \\
\hline LX9801 & $\mathrm{Ye} 502 / \mathrm{H} 21$ & SPT & 89.8 & 51.2 \\
\hline Huang428-3 & Huangzao4/E28 & SPT & 48.6 & 42.4 \\
\hline $\mathrm{Si} 287$ & $444 / 255$ & SPT & 17.6 & 13.8 \\
\hline $\mathrm{Si} 279$ & Huangzao4/428 & SPT & 84.4 & 51.5 \\
\hline Ji853 & Huangzao4/Zi330//Huangzao4 & SPT & 32.4 & 20.9 \\
\hline 374 & Huangzao4/Qun105//Duohuang15 & SPT & 8.1 & 3.8 \\
\hline Te70 & He344/422 & SPT & 9.7 & 4.2 \\
\hline B467 & $434 / 444$ & SPT & 2.5 & 1.1 \\
\hline Tianya4 & Wu109/Huangzao4 & SPT & 7.6 & 4.8 \\
\hline Suixi605 & $8941 / 444$ & SPT & 4.2 & 2.3 \\
\hline 434 & XL66/Hua94 & SPT & 6.7 & 5.9 \\
\hline Wu314 & Huangzao4//Wu302D/Huangbaolie & SPT & 6.9 & 9.6 \\
\hline Ji35 & Huangzao4/Jiduo142 & SPT & 4.7 & 11.0 \\
\hline L34 & Huangzao4/Mo17 & SPT & 2.3 & 1.9 \\
\hline L270 & Huangzao4/Qi319 & SPT & 2.5 & 2.9 \\
\hline
\end{tabular}


the mean disease incidence for 17 lines carrying the 'Huangzao4' genotype at the SNP PZE-102187687 locus was 56.1\%, which was much higher than that for other lines in this association panel (Table 3), with an average of $14.9 \%$.

Haplotypes for resistance to head smut. In this genome-wide association study, four SNP loci, PZE-102187486, PZE102187611, PZA00672.8, and PZE-102188421, were significantly $(P<0.0001)$ associated with disease incidence in the association panel, and 11 haplotypes harboring these four loci and SNP PZE102187687 were generated in 'Mo17', 'Huangzao4', and their derivatives (Table 3 ). In the association panel, 30 inbred lines were derivatives of 'Mo17', and 26 inbred lines were derived from 'Huangzao4'. The data showed that the mean disease incidence was $3.2 \%$ for 28 of these lines and was much lower than $39.8 \%$ in 'Zhong204' and 'H152' in the 30 derivatives of 'Mo17' (Table 1; Table 3). The favorable haplotype from 'Mo17' provided the major resistance to head smut in this panel.

\section{DISCUSSION}

Under natural field evaluations of head smut infection, Lu and Brewbaker (24) identified four QTLs on chromosomes 1, 3, 9, and 10, in 100 recombinant inbred lines derived from 'Hi34' and 'TZil7'. Lübberstedt et al. (18) found three QTLs in the filed trails in France, and eight QTLs in China, using $220 \mathrm{~F}_{2: 3}$ families from a cross between two European elite inbred lines, 'D32' and 'D145'. Environmental and genetic background effects caused some inconsistencies in estimation of the position and magnitude of the QTLs. Therefore, the QTL identified for head smut resistance in this study should be revalidated under artificial inoculation conditions.

Using artificial inoculation, $\mathrm{Li}$ et al. (21) identified five QTLs, one each on chromosomes 1, 3, and 8, and two on chromosome 2 , accounting for 5.0 to $43.7 \%$ of the phenotypic variance across four environments in $184 \mathrm{~F}_{2: 3}$ families derived from a
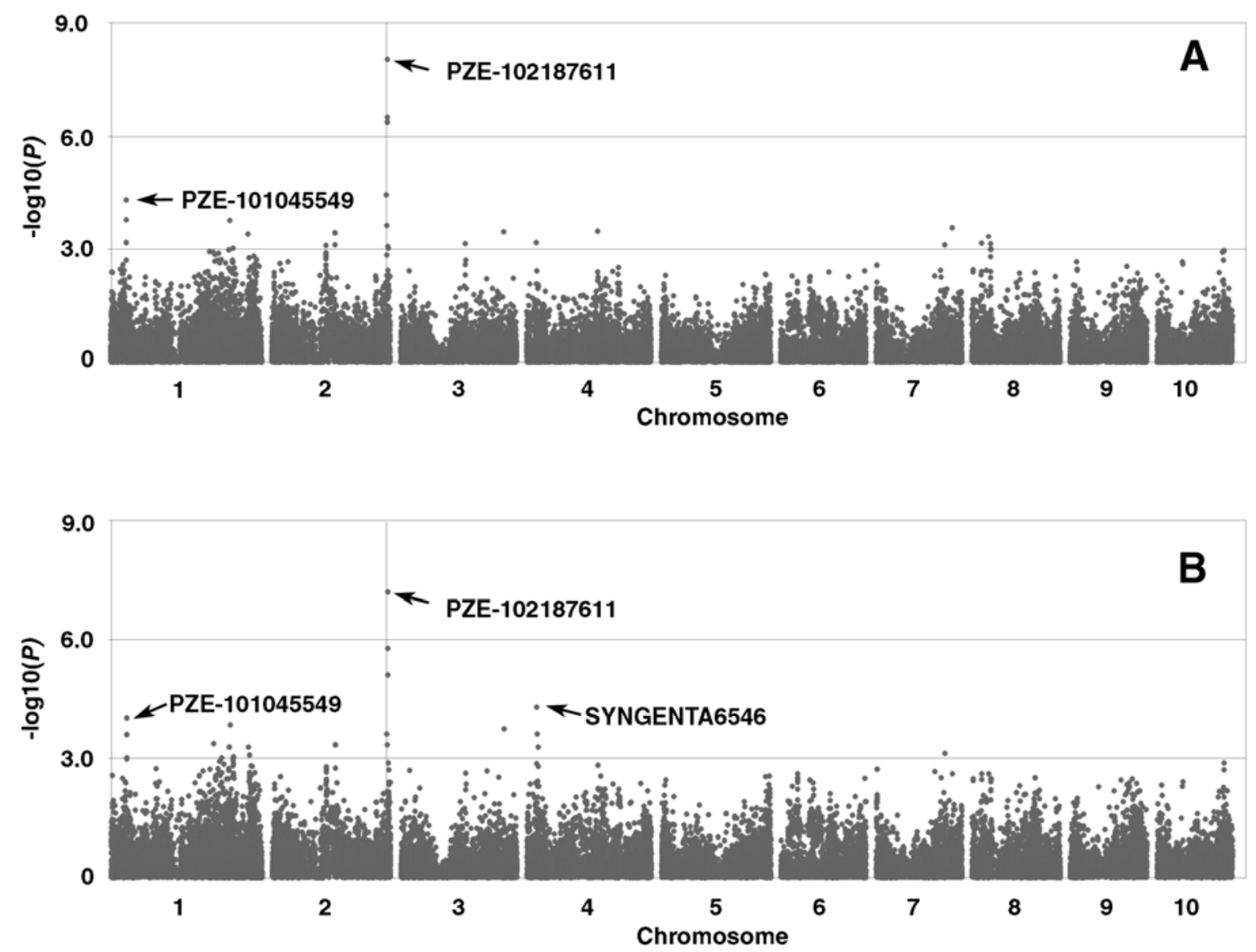

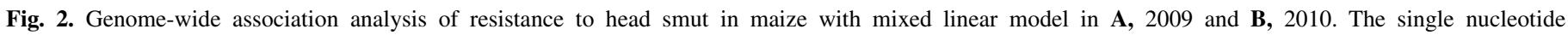

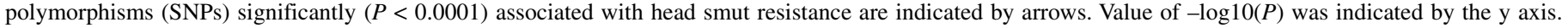
Position of the SNPs in $\mathbf{B}$ in 2.09 is indicated by the gray vertical line.

TABLE 2. Three quantitative trait loci (QTLs) for head smut resistance using a genome-wide association study in 2009 and 2010

\begin{tabular}{|c|c|c|c|c|c|c|c|c|}
\hline \multirow[b]{2}{*}{ QTL } & \multirow{2}{*}{$\begin{array}{l}\text { Single nucleotide } \\
\text { polymorphism }\end{array}$} & \multirow[b]{2}{*}{ Bin } & \multirow{2}{*}{$\begin{array}{l}\text { Physical } \\
\text { position }\end{array}$} & \multirow[b]{2}{*}{ Genotype } & \multicolumn{2}{|c|}{$P$ value } & \multicolumn{2}{|c|}{$R^{2}(\%)$} \\
\hline & & & & & 2009 & 2010 & 2009 & 2010 \\
\hline$q H S 1.03$ & PZE-101045549 & 1.03 & $31,582,444$ & AA/GG & $4.85 \mathrm{E}-05$ & $1.00 \mathrm{E}-04$ & 19.8 & 18.7 \\
\hline \multirow[t]{5}{*}{$q H S 2.09$} & PZE-102187486 & 2.09 & $231,382,602$ & $\mathrm{AA} / \mathrm{CC} /$--a $^{-}$ & $3.64 \mathrm{E}-05$ & $4.65 \mathrm{E}-04$ & 20.5 & 16.0 \\
\hline & PZE-102187611 & 2.09 & $231,660,578$ & AA/GG & $9.39 \mathrm{E}-09$ & $6.56 \mathrm{E}-08$ & 44.4 & 39.7 \\
\hline & PZE-102187687 & 2.09 & $231,712,426$ & AA/CC/-- & 8.70E-01 & $9.92 \mathrm{E}-01$ & $9.12 \mathrm{E}-04$ & $3.60 \mathrm{E}-06$ \\
\hline & PZA00672.8 & 2.09 & $232,004,713$ & AA/GG/-- & $3.21 \mathrm{E}-07$ & 7.99E-06 & 37.5 & 29.3 \\
\hline & PZE-102188421 & 2.09 & $232,381,945$ & AA/GG & $4.21 \mathrm{E}-07$ & $1.69 \mathrm{E}-06$ & 32.6 & 29.8 \\
\hline$q H S 4.03$ & SYNGEBTA6546 & 4.03 & $19,329,412$ & AA/GG & $6.78 \mathrm{E}-04$ & 5.32E-05 & 13.4 & 20.3 \\
\hline
\end{tabular}

a -- is the deletion in the SNP locus. 
cross between resistant 'Mo17' and susceptible 'Huangzao4'. The major QTL in bin 2.09 could explain up to $43.7 \%$ of the phenotypic variance in that panel. Chen et al. (9) found four QTLs on four chromosomal regions (bins 1.02/3, 2.08/9, 6.07, and 10.03/4) in the $\mathrm{BC}_{1}$ population derived from the highly resistant donor parent, 'Ji1037', and the highly susceptible recurrent parent, 'Huangzao4'. A major resistance QTL, qHSRl in bin 2.08/9, was detected and flanked by the markers SSR148152 and STS661. 'Ji1037' was originally derived from a cross between 'Mo17' and tropical germplasm (Table 1). The major QTL in bin 2.09 was probably transmitted from the same resistant donor, which was supported by the occurrence of a consistent haplotype between 'Ji1037' and 'Mo17' in this major QTL region (Table 3).

Differences in mean head smut incidence among six subgroups have been observed, with the highest level, 56.4\%, in the Si-pingtou group, and the lowest level, $1.8 \%$, in the Lancaster group (36). Similarly, relatively low disease incidence was observed in 37 Lancaster subgroup lines (Table 1), and one major resistance QTL, $q H S 2.09$, was detected across two environments in this association panel (Table 2; Fig. 2). Twenty-four derivatives of 'Mo17' carrying the favorable haplotype from 'Mo17' showed reduced disease incidence relative to $39.8 \%$ in 'Zhong204' and 'H152', with an average of $3.3 \%$ (Table 3 ). Therefore, the Lancaster germ-

TABLE 3. Analysis of diverse haplotypes generated with five closely linked single nucleotide polymorphisms (SNPs) in 'Mo17', 'Huangzao4', and their derivatives

\begin{tabular}{|c|c|c|c|c|c|c|c|}
\hline \multirow[b]{2}{*}{ Haplotype } & \multirow[b]{2}{*}{ Mean of incidence(\%) } & \multirow[b]{2}{*}{ Inbred lines $(\mathrm{M} / \mathrm{H})^{\mathrm{a}}$} & \multicolumn{5}{|c|}{ SNP genotypes } \\
\hline & & & PZE-102187486 & PZE-102187611 & PZE-102187687 & PZA00672.8 & PZE-102188421 \\
\hline \multirow[t]{31}{*}{$\mathrm{a}$} & 4.9 & Mo17(M) & $\mathrm{CC}$ & AA & AA & GG & AA \\
\hline & & Yu12(M) & $\mathrm{CC}$ & AA & AA & GG & AA \\
\hline & & J002(M) & $\mathrm{CC}$ & AA & AA & GG & AA \\
\hline & & Guan17(M) & $\mathrm{CC}$ & AA & AA & GG & AA \\
\hline & & Huotanghuang(M) & $\mathrm{CC}$ & AA & AA & GG & AA \\
\hline & & $\mathrm{C} 416(\mathrm{M})$ & $\mathrm{CC}$ & AA & AA & GG & AA \\
\hline & & $416(\mathrm{M})$ & $\mathrm{CC}$ & AA & AA & GG & AA \\
\hline & & Dan1324(M) & $\mathrm{CC}$ & AA & AA & GG & AA \\
\hline & & Ji846(M) & $\mathrm{CC}$ & AA & AA & GG & AA \\
\hline & & He344(M) & $\mathrm{CC}$ & AA & AA & GG & AA \\
\hline & & D185(M) & $\mathrm{CC}$ & AA & AA & GG & AA \\
\hline & & $4 \mathrm{~F} 1(\mathrm{M})$ & $\mathrm{CC}$ & AA & AA & GG & AA \\
\hline & & $\mathrm{J} 001(\mathrm{M})$ & $\mathrm{CC}$ & AA & AA & GG & AA \\
\hline & & Suixi701(M) & $\mathrm{CC}$ & AA & AA & GG & AA \\
\hline & & Ji992(M) & $\mathrm{CC}$ & AA & AA & GG & AA \\
\hline & & Ji1037(M) & $\mathrm{CC}$ & AA & AA & GG & AA \\
\hline & & D387(M) & $\mathrm{CC}$ & AA & AA & GG & AA \\
\hline & & M0113(M) & $\mathrm{CC}$ & AA & AA & GG & AA \\
\hline & & $5213(\mathrm{M})$ & $\mathrm{CC}$ & AA & AA & GG & AA \\
\hline & & $\mathrm{Si}-419(\mathrm{M})$ & $\mathrm{CC}$ & AA & AA & GG & AA \\
\hline & & Ji412(M) & $\mathrm{CC}$ & AA & AA & GG & AA \\
\hline & & Ji419(M) & $\mathrm{CC}$ & AA & AA & GG & AA \\
\hline & & Ji465(M) & $\mathrm{CC}$ & AA & AA & GG & AA \\
\hline & & $\mathrm{Ji} 495(\mathrm{M})$ & $\mathrm{CC}$ & AA & AA & GG & AA \\
\hline & & Longkang11(M) & $\mathrm{CC}$ & AA & AA & GG & AA \\
\hline & & $\mathrm{L} 34(\mathrm{H} / \mathrm{M})$ & $\mathrm{CC}$ & AA & AA & GG & AA \\
\hline & & Luyuan133(H) & $\mathrm{CC}$ & AA & AA & GG & AA \\
\hline & & $\mathrm{H} 201(\mathrm{H})$ & $\mathrm{CC}$ & AA & AA & GG & AA \\
\hline & & Ji853(H) & $\mathrm{CC}$ & AA & AA & GG & AA \\
\hline & & $374(\mathrm{H})$ & $\mathrm{CC}$ & AA & AA & GG & AA \\
\hline & & Tianya4(H) & $\mathrm{CC}$ & AA & AA & GG & AA \\
\hline \multirow[t]{8}{*}{$\mathrm{b}$} & 55.6 & Huangzao4(H) & AA & GG & -- & AA & GG \\
\hline & & Wenhuang $(\mathrm{H})$ & AA & GG & -- & AA & GG \\
\hline & & CN962(H) & AA & GG & -- & AA & GG \\
\hline & & $196(\mathrm{H})$ & AA & GG & -- & AA & GG \\
\hline & & Huangyesi(H) & AA & GG & -- & AA & GG \\
\hline & & $\mathrm{K} 12(\mathrm{H})$ & AA & GG & -- & AA & GG \\
\hline & & Dhuang212(H) & AA & GG & -- & AA & GG \\
\hline & & Zhonghuang204(M) & AA & GG & -- & AA & GG \\
\hline \multirow[t]{6}{*}{$\mathrm{c}$} & 55.9 & Huang428-3(H) & AA & GG & -- & -- & GG \\
\hline & & $\mathrm{Si} 279(\mathrm{H})$ & AA & GG & -- & -- & GG \\
\hline & & Sizhisi(H) & AA & GG & -- & -- & GG \\
\hline & & Chang7-2(H) & AA & GG & -- & -- & GG \\
\hline & & $\mathrm{Ye} 502(\mathrm{H})$ & AA & GG & -- & -- & GG \\
\hline & & H152(H/M) & AA & GG & -- & -- & GG \\
\hline $\mathrm{d}$ & 41.6 & $444(\mathrm{H})$ & AA & GG & -- & GG & AA \\
\hline e & 70.6 & PI42(H) & $\mathrm{CC}$ & GG & -- & AA & AA \\
\hline $\mathrm{f}$ & 61.7 & $\mathrm{H} 21(\mathrm{H})$ & $\mathrm{CC}$ & AA & -- & GG & AA \\
\hline \multirow[t]{4}{*}{$\mathrm{g}$} & 4.5 & JiA-034(M) & $\mathrm{CC}$ & AA & $\mathrm{CC}$ & GG & AA \\
\hline & & Ji842(M) & $\mathrm{CC}$ & $\mathrm{AA}$ & $\mathrm{CC}$ & GG & AA \\
\hline & & Wu314(H) & $\mathrm{CC}$ & AA & $\mathrm{CC}$ & GG & AA \\
\hline & & L270(H) & $\mathrm{CC}$ & AA & $\mathrm{CC}$ & GG & AA \\
\hline $\mathrm{h}$ & 55.1 & Jing7(H) & $\mathrm{CC}$ & GG & $\mathrm{CC}$ & GG & GG \\
\hline i & 7.8 & $\mathrm{Ji} 35(\mathrm{H})$ & -- & AA & AA & GG & AA \\
\hline j & 39.6 & Ye515(H) & -- & GG & AA & GG & AA \\
\hline $\mathrm{k}$ & 3.2 & C649(M) & AA & AA & AA & GG & AA \\
\hline
\end{tabular}

${ }^{a} \mathrm{M}$ is 'Mo17' inbred line or its derivatives, $\mathrm{H}$ is 'Huangzao4' inbred line or its derivatives. 
plasm group, including 'Mo17' and its derivatives, was an important source of resistance to head smut, and the QTL qHS2.09 was the major resistance locus in this subgroup. Selection for SNP PZE-102187611, closely linked to the resistance QTL in bin 2.09, could be undertaken to improve resistance to head smut in maize using 'Mo17' germplasm.

Maize is an ideal candidate system compared to self-crossing species for the application of association studies, because linkage disequilibrium decays more rapidly in maize (28). For instance, in rice, the GW2 gene that controls grain width and weight, has not been detected in association mapping with a panel of 517 rice landraces (14). But two homologs of this gene, $\mathrm{ZmGW2-CHR4}$ and $Z m G W 2-C H R 5$, were identified with significant associations with kernel width and other three yield-related traits in maize (kernel length, kernel thickness, and one-hundred kernel weight) (20). So far, numerous small-effect QTLs for flowering time, SLB resistance, NLB resistance, and leaf architecture have been identified in a maize NAM population $(7,17,29,35)$. Drought resistance QTLs were identified in an association panel with 350 tropical and subtropical maize inbred lines (32). In the present study, two subgroups including Lancaster and Si-ping-tou, were used for a genome-wide association study. Three QTLs for head smut resistance were detected in this association panel, including $q H S 1.03$ and $q H S 2.09$ that were relatively stable across two environments. This result confirms previous mapping of head smut resistance in an $\mathrm{F}_{2: 3}$ population of 'Mo17' $\times$ 'Huangzao4' (21), and a population derived from a cross of 'Ji1037' $\times$ 'Huangzao4' (9). Furthermore, $q H S 2.09$ was finely mapped into an interval of $\approx 1.10 \mathrm{Mb}$, flanked by SNP PZE-102187307 and PZE102188421 (Fig. 1B). It is interesting that the SNP PZE102187611, the locus most significantly $(P=9.39$ E-9) associated with disease incidence in the $q H S 2.09$ region, was also located in the introgression fragment of line L34 (Figs. 1 and 2). Then, the QTL $q H S 2.09$ was located between SNP PZE-102187486 and PZE-102188421 by combined linkage and association mapping within an interval of $\approx 1.00 \mathrm{Mb}$. A similar approach using joint linkage and association mapping has been explored to detect QTL underlying drought tolerance in maize (25). Now that many maize re-sequencing efforts have resulted in the generation of millions of SNPs useful for association, the high density of SNP markers will permit evaluation of potential candidate genes, detection of major QTL, and the definition of favorable alleles for many traits.

Together, these data show joint linkage and association mapping to be a powerful approach for detection of QTL underlying complex traits in maize. Lancaster germplasm has been one of the most important sources for head smut resistance in maize, and a favorable haplotype and markers identified in this study will facilitate the future selection of resistance genes among the segregating progenies for head smut resistance.

\section{ACKNOWLEDGMENTS}

This research was jointly funded by the National Basic Research Program of China (2011CB100100), the National Hi-Tech Research Program and Development Program of China (2012AA101104), and the International Cooperation Project for Science and Technology (2007DFA31010).

\section{LITERATURE CITED}

1. Akhtar, A., and Baggett, J. R. 1990. Inheritance of resistance to head smut disease in corn. J. Am. Soc. Hort. Sci. 115:668-672.

2. Atwell, S., Huang, Y. S., Vilhjalmsson, B. J., Willems, G., Horton, M., Li, Y., Meng, D., Platt, A., Tarone, A. M., Hu, T. T., Jiang, R., Muliyati, N. W., Zhang, X., Amer, M. A., Baxter, I., Brachi, B., Chory, J., Dean, C., Debieu, M., de Meaux, J., Ecker, J. R., Faure, N., Kniskern, J. M., Jones, J. D. G., Michael, T., Nemri, A., Roux, F., Salt, D. E., Tang, C., Todesco, M., Traw, M. B., Weigel, D., Marjoram, P., Borevitz, J. O., Bergelson, J., and Nordborg, M. 2010. Genome-wide association study of 107 phenotypes in Arabidopsis thaliana inbred lines. Nature 465:627-631.
3. Balint-Kurti, P. J., and Carson, M. L. 2006. Analysis of quantitative trait loci for resistance to southern leaf blight in juvenile maize. Phytopathology 96:221-225.

4. Balint-Kurti, P. J., Krakowsky, M. D., Jines, M. P., Robertson, L. A., Molnar, T. L., Goodman, M. M., and Holl, J. B. 2006. Identification of quantitative trait loci for resistance to southern leaf blight and days to anthesis in a maize recombinant inbred line population. Phytopathology 96:1067-1071.

5. Bernardo, R., Bourrier, M., and Olivier, J. 1992. Generation means analysis of resistance to head smut in maize. Agronomie 12:303-306.

6. Bradbury, P. J., Zhang, Z., Kroon, D. E., Casstevens, T. M., Ramdoss, Y., and Buckler, E. S. 2007. TASSEL: Software for association mapping of complex traits in diverse samples. Bioinformatics 23:2633-2635.

7. Buckler, E. S., Holland, J. B., Bradbury, P. J., Acharya, C. B., Brown, P. J., Browne, C., Ersoz, E., Flint-Garcia, S., Garcia, A., Glaubitz, J. C., Goodman, M. M., Harjes, C., Guill, K., Kroon, D. E., Larsson, S., Lepak, N. K., Li, H., Mitchell, S. E., Pressoir, G., Peiffer, J. A., Rosas, M. O., Rocheford, T. R., Romay, M. C., Romero, S., Salvo, S., Villeda, H. S., Sofia da Silva, H., Sun, Q., Tian, F., Upadyayula, N., Ware, D., Yates, H., Yu, J., Zhang, Z., Kresovich, S., and McMullen, M. D. 2009. The genetic architecture of maize flowering time. Science 325:714-718.

8. Carson, M. L., Stuber, C. W., and Senior, M. L. 2004. Identification and mapping of quantitative trait loci conditioning resistance to southern leaf blight of maize caused by Cochliobolus heterostrophus race $\mathrm{O}$. Phytopathology 94:862-867.

9. Chen, Y., Chao, Q., Tan, G., Zhao, J., Zhang, M., Ji, Q., and Xu, M. 2008. Identification and fine-mapping of a major QTL conferring resistance against head smut in maize. Theor. Appl. Genet. 117:1241-1252.

10. Cockram, J., White, J., Zuluaga, D. L., Smith, D., Comadran, J., Macaulay, M., Luo, Z., Kearsey, M. J., Werner, P., Harrap, D., Tapsell, C., Liu, H., Hedley, P. E., Stein, N., Schulte, D., Steuernagel, B., Marshall, D. F., Thomas, W. T. B., Ramsay, L., Mackay, I., Balding, D. J., Consortium, T. A., Waugh, R., and O'Sullivan, D. M. 2010. Genome-wide association mapping to candidate polymorphism resolution in the unsequenced barley genome. Proc. Natl. Acad. Sci. USA 107:21611-21616.

11. Duan, Y. Z., Li, X. X., Ai, F. Z., Yang, J. H., and Li, F. M. 1992. Selection and identification on resistance resource of corn head smut of Shanxi Province. Acta Agric. Boreali-occidentalis Sin. 1:83-86. (In Chinese with English abstract)

12. Gore, M. A., Chia, J. M., Elshire, R. J., Sun, Q., Ersoz, E. S., Hurwitz, B. L., Peiffer, J. A., McMullen, M. D., Grills, G. S., Ross-Ibarra, J., Ware, D. H., and Buckler, E. S. 2009. A first-generation haplotype map of maize. Science 326:1115-1117.

13. Hardy, O. J., and Vekemans, X. 2002. SPAGeDi: A versatile computer program to analyse spatial genetic structure at the individual or population levels. Mol. Ecol. Notes 2:618-620.

14. Huang, X. H., Wei, X. H., Sang, T., Zhao, Q., Feng, Q., Zhao, Y., Li, C. Y., Zhu, C. R., Lu, T. T., Zhang, Z. W., Li, M., Fan, D. L., Guo, Y. L., Wang, A. H., Wang, L., Deng, L. W., Li, W. J., Lu, Y. Q., Weng, Q. J., Liu, K. Y., Huang, T., Zhou, T. Y., Jing, Y. F., Li, W., Lin, Z., Buckler, E. S., Qian, Q., Zhang, Q. F., Li, J. Y., and Han, B. 2010. Genome-wide association studies of 14 agronomic traits in rice landraces. Nat. Genet. 42:961-967.

15. Innes, N. L. 1992. Gene banks and their contribution to the breeding of disease resistant cultivars. Euphytica 63:23-31.

16. Kruger, W. 1962. Sphacelotheca reiliana on maize. I. Infection and control studies. South Afr. J. Agric. Sci. 5:43-56.

17. Kump, K. L., Bradbury, P. J., Wisser, R. J., Buckler, E. S., Belcher, A. R., Oropeza-Rosas, M. A., Zwonitzer, J. C., Kresovich, S., McMullen, M. D., Ware, D., Balint-Kurti, P. J., and Holland, J. B. 2011. Genome-wide association study of quantitative resistance to southern leaf blight in the maize nested association mapping population. Nat. Genet. 43:163-168.

18. Lübberstedt, T., Xia, X. C., Tan, G., Liu, X., and Melchinger, A. E. 1999. QTL mapping of resistance to Sporisorium reiliana in maize. Theor. Appl. Genet. 99:593-598.

19. Li, B. Y., Zheng, T. J., and Guo, Y. L. 2005. Study on inducing condition of maize head smut. J. Mazie Sci. 13:121-123. (In Chinese with English abstract)

20. Li, Q., Li, L., Yang, X. H., Warburton, M., Bai, G. H., Dai, J. R., Li, J. S., and Yan, J. B. 2010. Relationship, evolutionary fate and function of two maize co-orthologs of rice $G W 2$ associated with kernel size and weight. BMC Plant Bio. 10:143.

21. Li, X. H., Wang, Z. H., Gao, S. R., Shi, H. L., Zhang, S. H., George, M. L. C., Li, M. S., and Xie, C. X. 2008. Analysis of QTL for resistance to head smut (Sporisorium reiliana) in maize. Field Crops Res. 106:148155.

22. Lindhout, P. 2002. The perspectives of polygenic resistance in breeding for durable disease resistance. Euphytica 124:217-226.

23. Liu, K. J., and Muse, S. V. 2005. PowerMarker: An integrated analysis environment for genetic marker analysis. Bioinformatics 21:2128-2129. 
24. Lu, X. W., and Brewbaker, J. L. 1999. Molecular mapping of QTLs conferring resistance to Sphacelotheca reiliana (Kühn) Clint. Maize Genet. Cooperation Newsl. 73:36.

25. Lu, Y. L., Zhang, S. H., Shah, T., Xie, C. X., Hao, Z. F., Li, X. H., Farkhari, M., Ribaut, J. M., Cao, M. J., Rong, T. Z., and Xu, Y. B. 2010. Joint linkage-linkage disequilibrium mapping is a powerful approach to detecting quantitative trait loci underlying drought tolerance in maize. Proc. Natl. Acad. Sci. USA 107:19585-19590.

26. Murray, M. G., and Thompson, W. F. 1980. Rapid isolation of high molecular weight plant DNA. Nucleic Acids Res. 8:4321-4326.

27. Nemri, A., Atwell, S., Tarone, A. M., Huang, Y. S., Zhao, K., Studholme, D. J., Nordborg, M., and Jones, J. D. G. 2010. Genome-wide survey of Arabidopsis natural variation in downy mildew resistance using combined association and linkage mapping. Proc. Natl. Acad. Sci. USA 107:1030210307.

28. Nordborg, M. 2000. Linkage disequilibrium, gene trees and selfing: An ancestral recombination graph with partial self-fertilization. Genetics 154:923-929.

29. Poland, J. A., Bradbury, P. J., Buckler, E. S., and Nelson, R. J. 2011. Genome-wide nested association mapping of quantitative resistance to northern leaf blight in maize. Proc. Natl. Acad. Sci. USA 108:6893-6898.

30. Pritchard, J. K., Stephens, M., and Donnelly, P. 2000. Inference of population structure using multilocus genotype data. Genetics 155:945-959.

31. Ramakrishna, W., Emberton, J., Ogden, M., SanMiguel, P., and Bennetzen, J. L. 2002. Structural analysis of the maize Rpl complex reveals numerous sites and unexpected mechanisms of local rearrangement. Plant Cell 14:3213-3223.

32. Setter, T. L., Yan, J. B., Warburton, M., Ribaut, J. M., Xu, Y. B., Sawkins, M., Buckler, E. S., Zhang, Z. W., and Gore, M. A. 2011. Genetic association mapping identifies single nucleotide polymorphisms in genes that affect abscisic acid levels in maize floral tissues during drought. J. Exp. Bot. 62:701-716.

33. Song, S. Y., Sun, X. H., Guo, W. G., and Liu, J. R. 2000. Identification of germplasm for resistance to head smut in maize. Agric. Sci. Jilin 25:3233. (In Chinese with English abstract)

34. Stromberg, E. L., Stienstra, W. C., Kommedahl, T., Matyac, C. A.,
Windels, C. E., and Geadelmann, J. L. 1984. Smut expression and resistance of corn to Sphacelotheca reiliana in Minnersota. Plant Dis. 68:880-884.

35. Tian, F., Bradbury, P. J., Brown, P. J., Hung, H., Sun, Q., Flint-Garcia, S., Rocheford, T. R., McMullen, M. D., Holland, J. B., and Buckler, E. S. 2011. Genome-wide association study of leaf architecture in the maize nested association mapping population. Nat. Genet. 43:159-162.

36. Wang, Z. H., Li, X. H., Xie, C. X., Li, M. S., Hao, Z. F., Xiao, M. J., Gao, S. R., and Zhang, S. H. 2008. Genetic diversity in a collection of chinese maize inbred lines for resistance to head smut caused by Sporisorium Reiliana. Maydica 53:47-54.

37. Welz, H. G., and Geiger, H. H. 2000. Genes for resistance to northern corn leaf blight in diverse maize populations. Plant Breed. 119:1-14.

38. Wisser, R. J., Balint-Kurti, P. J., and Nelson, R. J. 2006. The genetic architecture of disease resistance in maize: A synthesis of published studies. Phytopathology 96:120-129.

39. Wisser, R. J., Kolkman, J. M., Patzoldt, M. E., Holland, J. B., Yu, J., Krakowsky, M., Nelson, R. J., and Balint-Kurti, P. J. 2011. Multivariate analysis of maize disease resistances suggests a pleiotropic genetic basis and implicates a GST gene. Proc. Natl. Acad. Sci. USA 108:7339-7344.

40. Wu, X. L., Pang, Z. C., Tian, L. M., and Hu, J. C. 1981. On the environmental factors affecting infection and cultural measures of controlling corn head smut (Sphacelotheca Reilian (Kuhn) Clint.). J. Plant Prot. 8:4146. (In Chinese with English abstract)

41. Xia, X., Melchinger, A. E., Kuntze, L., and Lubberstedt, T. 1999. Quantitative trait loci mapping of resistance to Sugarcane mosaic virus in maize. Phytopathology 89:660-667.

42. Xie, C. X., Zhang, S. H., Li, M. S., Li, X. H., Hao, Z. F., Bai, L., Zhang, D. G., and Liang, Y. H. 2007. Inferring genome ancestry and estimating molecular relatedness among 187 Chinese maize inbred lines. J. Genet. Genomics 34:738-748.

43. Zwonitzer, J. C., Coles, N. D., Krakowsky, M. D., Arellano, C., Holland, J. B., McMullen, M. D., Pratt, R. C., and Balint-Kurti, P. J. 2010. Mapping resistance quantitative trait loci for three foliar diseases in a maize recombinant Inbred line population evidence for multiple disease resistance. Phytopathology 100:72-79. 